\title{
Consent to Medical Treatment and the Autonomous Power of Adult Patients: The Malaysian Legal Position
}

\author{
Tengku Noor Azira Tengku Zainudin, ${ }^{1}$
}

Anita Abdul Rahim²

\section{Ramalinggam Rajamanickam ${ }^{3}$}

\author{
${ }^{1}$ Faculty of Law, Universiti Kebangsaan Malaysia (UKM), 43600 Bangi, Selangor Darul Ehsan, Malaysia \\ tna@ukm.edu.my \\ 2Faculty of Law, Universiti Kebangsaan Malaysia (UKM), 43600 Bangi, Selangor Darul Ehsan, Malaysia \\ aar@ukm.edu.my \\ ${ }^{3}$ Faculty of Law, Universiti Kebangsaan Malaysia (UKM), 43600 Bangi, Selangor Darul Ehsan, Malaysia \\ rama@ukm.edu.my
}

\section{Doi:10.5901/mjss.2015.v6n4s3p418}

\section{Abstract}

A patient has the exclusive rights to determine what he wants or do not want to be done to his body. In this context, consent becomes a crucial factor that must be present before a doctor is allowed to treat his patient. Under the common law, an adult patient has the legal rights to determine the treatment that he wish to undergo and will subsequently consent to. This must be done when that patient still has the capacity to give consent and it must be given voluntarily without interference by any person. This relates to the rights of an individual patient to make decision autonomously whether to give consent or to refuse to give consent. In view of this legal position, the issue that will be the focus of discussion in this article is whether a patient who has the right to give consent also has the same right to refuse treament in Malaysia. Therefore it is the aim of this article to examine the law relating to consent to medical treatment by an adult patient in Malaysia together with the right of refusal.It is found that in order to exercise his autonomous power, a patient has the right to give or to refuse to give consent. This right exists even where the patient had lost his capacity to do so. The method of making the consent or refusal is known to the attending doctor (s) is an area that must be further researched on. This can be done by srutinising the role of an Advance Medical Directive in conveying the consent to medical treatment or the refusal thereof of an incapacitated patientand therole of the proxy appointed to execute the directive. Therefore this article can serve as a basis for the enactment of a specific statute addressing this issue.

Keywords: Consent; medical treatment; refusal; Advance Medical Directive; proxy

\section{Introduction}

As a general rule, medical procedures can be carried out only after the patients have giventheir consent (Mason, J.K.., et al., 2002). Thus the validity of a medical treatment depends very much on whether a legally valid consent has been obtained from the patient. In the event that no consent has been given but the treatment was still given to the particular patient, then that patient has the legal rights to commence a civil action against the doctor giving the treatment under the law of torts, specifically, for battery (Kennedy, I. \& Grubb, A., 1998). Battery is one component in the tort law of trespass against person. In the English case, Airedale NHS Trust v Bland (1993) A.C 789,Lord Keith had stated that:

"It is unlawful, so as to constitute both a tort and the crime of battery, to administer medical treatment to an adult who is conscious and of sound mind, without his consent." ((1993) A.C. 857)

The abovementioned law aims to protect the integrity of an individual and at the same time, gives protection to him from any unwanted intervention (Mendelson, D.,2002).Justice McHugh in Secretary, Department of Health \& Community Services (NT) v JWB and SMB (Marion's case) summed it up as below:

"It is the central thesis of the common law doctrine of trespass to the person that the voluntary choices and decisions of an adult person of sound mind concerning what is or is not done to his or her body must be respected and accepted, irrespective of what others, including doctors, may think is in the best interests of that particular person" (175 C.L.R. 218,309 (1992) 
The condition that a patient must consent before any medical treatment can be carried out indicates that a patient has the right to choose whether to consent or to refuse to give consent to any proposed medical treatment (Jones, M.A., 1991). The absence of the required consent will expose the attending doctor to an action under the law of trespass to person, specifically, battery. In fact inRe F (Mental Patient: Sterilisation)(1990) 2 A.C. 1,12, Lord Donaldson, MR stated that prima facie, all or almost all medical treatment dan surgical procedures on an adult patient will be invalid if no consent had been given, regardless of the fact that the treatment is for the benefit of the affected patient.

However, legal developments showed that almost all cases involving patients and doctors are based on the issue of failure on the part of doctors to disclose adequate information and risk involved in the proposed treatment to patients before they give their consent. In this situation, any consent given prior to the treatment is considered legally valid. The affected patient can however sue the doctor involved for medical negligence for failing to disclose adequate information and warn him of the risks involved in the treatment whererby in his case, the risks did in fact, materialize. The focus has shifted from the issue of unwanted bodily contact(battery) to failure to disclose relevant information and risks to the patient. This is because disclosure of information and risks will allow patients to make an informed decision and thereafter give an informed consent. This development in the relationship between doctor and patient has relegatedthe need to obtain consent as a part of a doctor's duty under the law of medical negligence.

In Chatterton v Gerson(1981) 1 QB 432,Justice Bristow held that failure to disclose inherent risks present in the medical procedure will not vitiate any consent given by the patient. The consent is still valid in law but the doctor had committed a breach in his duty to give advice. This breach is to be dealt with under the law of medical negligence and not trespass, specifically, battery.

Therfore, cases where doctors are being sued for battery are very few and are limited to situations where medical treatment was given even when patients have not in the first place consentedto the treatment.

\section{Research Materials and Methodology}

This legal research used a qualitative method in achieving the objectives of the research. Relevant materials for the research have been collected by way of library research. The data for this research was collected through primary and secondary sources. The decided cases have been used as main source of research. The method of critical analysis was also used in analyzing the relevant materials, data and information collected in this research.

\section{Elements of a Valid Consent}

The validity of a consent for a medical treatment depends on whether the patient had given a legally valid consent. Three elements must be fulfilled in order to render a consent legally valid:

1- The patient must have the capacity to give consent.

2- The patient was given adequate information relating to the nature of medical treatment proposed to be done.

3- The consent must be given voluntarily.

Therefore, it can be seen that for a consent to be a legally valid consent, the patient must have the mental capacity to give that consent, it is given voluntarily and after given adequate information relating to the proposed treatment. Capacity plays a major role in determining whether decision made by a patient to undergo medical treatment is legally valid or not and in this paper, discussion will focus on that first element as it is the most relevant element to the topic.

Under the common law the presumption is that an adult patient has the capacity to give consent. In $\operatorname{Re} T$ (Adult: Refusal Of Medical Treatment), Lord Donaldson had reiterated that:

"The right to decide one own's fate presupposes a capacity to do so. Every adult is presumed to have that capacity, but it is a presumption which can be rebutted."((1992) All ER 649,661)

Also in the case of Re MB (Medical Treatment)(1997)2 F.C.R. 541,Butler-Sloss, LJ stated that:

"Every person is presumed to have the capacity to consent to or to refuse medical treatment unless and until that presumption is rebutted."

In the case of $\operatorname{Re} F$, Lord Brandon had stated that the test on determining trhe capacity of a patient is:

"... whether the patient is able to understand the nature or purpose of an operation or treatment." ((1990) 2 AC 1, 55) 
Therefore, if an adult patient understands the information given by his doctor regarding the nature or purpose of an operation or treatment, then it can be said that he has capacity.

The legal position that an adult patient with mental capacity has the right to make his own decision and give his own consent signifies the respect given to an individual being to exercise his autonomous rights. In exercising his autonomy, an adult patient has the freedom recognized by law, to choose whether to consent to medical treatment or not.

In the case of Re T (Adult: Refusal of Treatment) (1992) All ER 649, 653, the English Court of Appeal confirmed that an adult patient with capacity has absolute right to give consent or refuse to give consent to a proposed treatment. Lord Donaldson again stated that:

"An adult patient who...suffers from no mental incapacity has an absolute right to choose whether to consent to medical treatment, to refuse it or to choose one rather than another treatments being offered."((1992) All ER 649,653)

Having understood that the legal position of the adult patient to give consent is as decided by the cases mentioned above, the discussion below will then proceed to identify the law relating to the right of an adult patient to give consent in Malaysia.

\section{The Legal Scenario in Malaysia}

The Malaysian Medical Council has a written Code of Medical Ethics that contains ethical guidelines that must be followed by the medical practitioners or doctors (Malaysian Medical Council, Code of Medical Ethics). Part II of the said Code has a heading entitled Ethical Obligations of Doctors to Patient. The first principle is on the duty to obtain consent from patients. This principle provides that in order to enable patients to make a decision regarding their health treatment, those patients must be given adequate information. That information must be conveyed to patients in the best possible way so that it can be understood. At the same time, there is also the Patients' Charter which is a document cointaining the codes of medical ethics. Part IV of the Charter lays down the requirement to obtain consent from patients before any medical preocedures or treatment can be carried out.

It is clear that in Malaysia there is no specific comprehensive statute on consent to medical treatment. One exception being cases involving mental health patients whereby the governing law is the Malaysian Mental Health Act 2001 which has a specific provision on consent.However, this Act only applies to those suffering from mental illness and are governed by the provisions of the Act. Even though in Malaysia there exist the abovementioned Code of Medical Ethics and Patients' Charter, those two documents actually have no legal bearing or are legally toothless. However, the MMC has the power to take disciplinary action against practioners who do not adhere to the guidelines (Medical Act 1971 section 4, section 29(1) dan (2)).Non-conformity with the laid down guidelines have no actual legal consequences.

Nevertheless, as Malaysia is a Commonwealth country, the English common law is applicable where there are no written laws or statutes in that particular area. Hence, as at the moment there is no specific statute dealing with consent to treatment, the common law position as discussed above will be applicable in any legal dispute regarding consent to medical treatment. This means that under the law, a doctor must first obtain the consent of his patient before proceeding with a proposed treatment. In order to get that consent, the patient must be furnished with adequate relevant information for instance, the nature of the proposed treatment, inherent risks involved and also the availability of alternative treatments. This information must be disclosed to the adult patient so that he can make an informed decision and subsequently give an informed consent. Failure to adhere to this legal requirement can expose the doctor involved to a medical negligence suit should the undisclosed risks materialized and the patient suffered harm.

In a nutshell, an adult patient with the required mental capacity, has the right to give consent to give consent to any proposed medical treatment. This paper will now look into the issue of whether a patient who has the right to give consent has also the corresponding right to refuse treament in Malaysia. The background of the common law position will be first highlighted as the principles from the cases decided by the English courts are applicable under the Malaysian legal system.

\section{The Common Law Scenario: Refusal to Give Consent-}

Decided cases showed that there were situations where patients had chosen to refuse to give consent to medical treatment even though it was for the well being of their own health.This right to refuse goes against the accepted medical ethics where doctors were trained to treat and also to save lives. When patients refuse to undergo treatment proposed for their own good, this means that doctors can no longer proceed with their responsibility to treat their patients (Berg, W.B., 
et. al., 2001). But the law is crystal clear in that an adult patient who has the required mental capacity must first give consent to make any treatment carried out on him legally valid and thus protect the attending doctor from a legal dispute (Re T (An Adult: Refusal of Medical Treatment) (1992) 4 All ER 649).

The case of Re C (Adult: Refusal of Medical Treatment) (1994) 1 All ER 819 illustrates how the law distinguish between capacity and the rationality of the decision made by a patient.In this case, $\mathrm{C}$ was a schizophrenic prisoner. His leg suffered from gangrene and was advised to undergo amputation of the bad leg. Refusal to do so can jeopardise his life and can cause death. $\mathrm{C}$ refused to give consent as he did not believe that if the leg was not amputated, it has a high risk of causing death.

In this case, Justice Thorpe agreed with the dicta by Lord Donaldson in Re T where His Lordship stated that each adult patient has the right and capacity to accept or refuse to accept medical treatment. The legal principle is that:

"Prima facie every adult has the right and capacity to decide whether or not he will accept medical treatment, even if a refusal may risk permanent injury to his health or even lead to premature death...(Re T(Adult: Refusal of Treatment) (1992) 4 All ER 649, 664)

Justice Thorpe was of the opinion that when $\mathrm{C}$ made his decision, $\mathrm{C}$ had the required mental capacity to understand the information given to him and was therefore able to make his own decision. In another case, St. George's Healthcare NHS Trust v S, R v Collins and others, ex p S (1998) 3 All ER 673, a pregnant woman sufferd from preenclampsia and was advised by her doctor to have an induced labour. If labour is not induced, the condition can threatened her life and also the life of her unborn fetus. The patient refused to give consent even though she understood the grave consequences of her refusal as she wanted to have a normal birth. The Court of Appeal decided that a woman who is pregnant but competent has the absolute right to refuse to receive medical treatment. The Court reiterated that:

"Even when her own life depends on receiving medical treatment, an adult of sound mind is entitled to refuse it. This reflects the autonomy of each individual and the right of self-determination." ((1998) 3 All ER 673)

The decision in the case of Re B (Adult: Refusal of Medical Treatment) (2002) 2 All ER 449 also affirmed the legal position that a competent patient has the right to refuse medical treatment eventhough by refusing to accept medical treatment, it can cause him death.

In cases where a patient with capacity refuses to accept treatment due to religious belief, the court was consistent that the refusal is legally valid and acceptable. Butler-Sloss, LJ, obiterin Re M.B:

"A competent woman who has the capacity to decide may, for religious reasons, other reasons, for rational or irrational reasons or for no reason at all, choose not to have medical intervention, even though...the consequence may be death or serious handicap of the child she bears, or her own death. She may refuse to consent to the anaesthesia injection in the full knowledge that her decision may significantly reduce the chance of her unborn child being alive."(Re M.B (An Adult: Medical Treatment) (1997)2 F.C.R. 541, 553, 561)

Therefore, it can be concluded that the common law position in the matter of refusal to give consent is clear. A patient who has been given the necessary and adequate information such as the nature of the treatment and the inherentrisks presence, can refuse to give consent to medical treatment. The doctors must on their part respect any decision made by their patients be it to give consent or to refuse to give consent. Proceeding with treatment without having the necessary consent is legally wrong and it can tantamount to a trespass to person. Kennedy opined that the one of the basic elements of the common law is respect to the right of individual freedom.Medico-legal wise, this means that the law protects the right of patients ro make their own decision in matters affecting their bodies (Kennedy, I, 1998).

However, the dilemma begins when a previously competent patient loses that mental capacity and is consequently unable to communicate his preference regarding his medical treatment. It is to be noted that under the common law, a next of kin has no legal standing to give consent to an incapacitated patient. Doctors on the other hand can only give unconsented treatment in an emergency situation where immediate treatment must be given but the patient is unconscious and is not able to give consent. This is based on the best interest of the patient principle. This principle however cannot be applied where the patient does not have the necessary capacity to give consent and yet the situation is not an emergency.

The question now is, how can the consent or refusal to give consent be communicated to the doctors in situations where the patient has become incapacitated? The authors will now look into one possible solution to the problem and that is the preparation of an advance directive. 


\section{Solving the Problem: Advance Medical Directive}

Advance Medical Directive is a document which contained directives by a patient specifying the types of treatment that he will allow to be administered to him and those that are not allowed when he had became incapacitated.

Advance Medical Directives enable patients to have a voice or a say in circumstances when they no longer have control over what is being done to them. Thus it can be said that an advance directive gives a patient the power and right to choose and decide what he wants to be done to him treatment wise, before he loses the mental capacity to do so (Sommerville, A., 1996).

A patient who desires to make an advance directive must be legally competent. As has been stated above, an adult patient has an absolute right to refuse to give consent to medical treatment regardless of whether the decision is rational or not. Thus, any directive specified by a patient while he has capacity to refuse to give consent, is legally binding and effective in the subsequent circumstances when he lost that capacity (Kennedy, I. and Grubb, A, 1998).

Legally, a patient can only make an Advance Medical Directive regarding his decision to refuse to accept treatment but he is not legally allowed to make directive to demand a particular type of treatment. As an example, a patient who has capacity realizes that he is going to lose that capacity in the future due to his medical condition. He then chooses to prepare an Advance Medical Directive laying down the type of treatments decided by the doctors that he will accept and also the type of treatment that he refuses to accept (Dickens, B., 1997).

Lord Keith, in the case of Bland(1993) 1 All ER 821, 860 stated that the freedom of a competent patient to refuse to undergo treatment even if it meant death, is also applicable to situation where he can foresee losing his capacity in the future and therefore make a directive specifying his refusal to accept life-prolonging treatment. The decision will be valid as if it was made by a patient with capacity.

British Medical Associationsuggested that patients who plan to have an Advance Medical Directive prepared, must first get medical advice and opinion from his doctor(s). This is to ensure that he understands the risks and also the benefits of having an advance directive. The doctor involved must also provide his patient with information on the diagnosis, prognosis and treatment options that areavailable (The Law Commission Consultation Paper No. 129, 1993).

The patient who opted to make an Advance Medical Directive may wish to appoint a proxy who will have the power to execute the said directive. Generally the decision to consent or to refuse medical treatment is made by the patient and it will be stated in the directive. The proxy will only carry out the wishes of the patient. However, there are situations where the patient gives the power to make decision on whether to give consent or not to the proxy. In this regard, the proxy will be the one who decides and executes the directive. In this circumstance, whatever decision made by the proxy will be considered as the decision of the patient as the proxy is acting on behalf on the patient. The proxy can be appointed from family members, relatives, friends or any other person trusted by the patient

In Malaysia, again, as there is no statute pertaining to consent to medical treatment, the position under the common law will apply. In the United Kingdom there is now the Mental Capacity Act 2005 that has a specific provision on advance directive. Therefore the writers are of the opinion that refusal to give consent can be made by way of an Advance Medical Directive in preparation for the time when the patient no longer has the capacity to communicate his decision to his doctor. The writers are also of the opinion that there should be a special guidelines regarding advance directive specifying the circumstances on when it can be done, the way to prepare it and the form in which it should be prepared. The same patient must be given the freedom to choose whoever he prefers and trusts to be his proxy in relation to the Advance Medical Directive.

\section{Concluding Remarks}

Consent to medical treatment lies at the root of the relationship between a doctor and his patient. Consent must be given voluntarily by a patient who has the capacity to do so, after receiving adequate information in order for it to be a legally valid consent.Failure to obtain the consent of his patient before starting with medical treatment will expose the doctor to a civil suit whether for trespass or medical negligence. Under the concept of patient autonomy recognized by law, a patient has the right to make his own decision whether to give consent or to refuse to give consent regardless of whatever reason, rational or not. The most important thing is to ensure that the patients must be allowed to exercise their rights and this include to right to make an advance decision regarding their medical treatment. Decision to give consent to medical treatment or to refuse to give consent in the event where the patient had became incapacitated must be communicated to the doctor(s) and this can be achieved by way of an Advance Medical Directive.

It is our humbly suggestion that there should be a specific Act addressing this issue. Malaysia can take the first step towards reforming this area of law by looking to its neighbour, Singapore regarding Advance Medical Directive and 
consent to treatment involving incapacitated patients. Singapore had passed a law called the Mental Capacity Act 2008 to deal with matters pertaining to incapacitated patient and this includedAdvance Medical Directice.

\section{References}

Medical Act 1971

Malaysian Medical Council, Code of Medical Ethics)

Mental Health Act 2001

Mental Capacity Act 2005

M Mendelson, D., Historical Evolution and Modern Implications Concepts of Consent To and Refusal of, Medical Treatment in the Law of Trespass, The Journal of Legal Medicine, 17.

Mason, J.K..., et al., Law and Medical Ethics, Butterworths LexisNexis, London, 2002.

Kennedy, I. \& Grubb, A.,(pnyt), Principles of Medical Law, Oxford University Press, Oxford, 1998.

Kennedy, I., Treat Me Right, Essays In Medical Law And Ethics, Clarendon Press, Oxford, 1988

Sommerville, A., Are Advance Directives Really The Answer? And What Was The Question?,inMclean, S. (ed), Death, Dying And The Law, Dartmouth, Aldershot, 1996, p.20, in McLean, S., Medical Law And Ethics, Ashgate Dartmouth, Aldershot, 2002.

Dickens, B., Legal Aspects Of Dementia, The Lancet,; Mar 29, 1997; 349, 9056; 948

The Law Commission Consultation Paper No. 129, Mentally Incapacitated Adults And Decision-Making, Medical Treatment And Research, HMSO, London, 1993.

Jones, M.A., Medical Negligence, Sweet \& Maxwell, London, 1991.

Airedale NHS Trust $v$ Bland (1993) A.C 789

Secretary, Department of Health \& Community Services (NT) v JWB and SMB 175 C.L.R. 218,309 (1992)

Chatterton v Gerson (1981) 1 QB 432

Re F (Mental Patient: Sterilisation), (1990) 2 A.C. 1, 12

Re MB(Medical Treatment) (1997)2 F.C.R. 541

Re T (Adult: Refusal of Treatment) (1992) All ER 649,653

Re B (Adult: Refusal Of Medical Treatment) (2002) 2 All ER 449

St. George's Healthcare NHS Trust v S , R v Collins and others, exp S (1998) 3 All ER 673, 